\title{
Is Diagnostic Cystoscopy Painful? Analysis of 1,320 Consecutive Procedures
}

\author{
Alexander Greenstein ${ }^{1}$, Ithamar Greenstein², Solomon Senderovich ${ }^{3}$, Nicola J. Mabjeesh ${ }^{1}$ \\ ${ }^{1}$ Department of Urology, Tel Aviv Sourasky Medical Center, Sackler Faculty of Medicine, Tel-Aviv Univer- \\ sity, Tel Aviv; ${ }^{2}$ Hebrew University Hadassah Medical School, Jerusalemv and ${ }^{3}$ Assuta Hashalom Medical \\ Center, Assuta Medical Centers (SS), Tel Aviv, Israel
}

\section{ABSTRACT}

Objective: To prospectively evaluate self-reported pain levels associated with diagnostic cystoscopy.

Materials and Methods: Patients who underwent diagnostic cystoscopy and subsequently graded their pain level during the procedure were enrolled. Pain was graded on a Likert visual analog scale (VAS) of 1-10 where $0=$ no pain and $10=$ excruciating unbearable pain. Local lidocaine gel 2\% was used as intraurethral lubricant.

Results: Data from 1320 consecutive cystoscopies (929 males, 391 females, age range 15-93 years) between 6/2009-1/2010 were analyzed. This was the first cystoscopy for 814 patients. The overall mean VAS was $2.74 \pm 1.51$ (range 0-9) for rigid cystoscopy and $2.48 \pm 1.53$ (range $0-10)$ for flexible cystoscopy $(\mathrm{P}=0.004)$. The reported mean pain level for first-time cystoscopy was significantly higher than that for repeat cystoscopy $(2.8 \pm 1.6$ vs. $2.2 \pm 1.4, \mathrm{P}<0.001)$, regardless of gender or type of cystoscope. Men reported significantly higher pain levels than women $2.6 \pm 1.5$ vs. $2.4 \pm 1.4(\mathrm{P}<$ 0.04). The highest mean pain level was reported by men $(3.4 \pm 1.6)$ and women $(2.5$ $\pm 1.6)$ for rigid cystoscopy compared to flexible cystoscopy $(2.5 \pm 1.4$ and $1.1 \pm 1.9$, respectively, $\mathrm{P}<0.001)$. Pain levels $>5$ were reported in 75 (5.7\%) cystoscopies.

Conclusions: Cystoscopy was not associated with distressing levels of pain. Pain levels during first cystoscopies were higher than those for repeated ones. Using a flexible cystoscope is associated with a lower pain level in both men and women and it should be used for both genders.

\section{ARTICLE INFO}

Key words:

Cystoscopy; Lower Urinary Tract

Symptoms; Urologic Surgical

Procedures, Male

Int Braz J Urol. 2014; 40: 533-8

Submitted for publication:

September 01, 2013

Accepted after revision:

January 14, 2014

\section{INTRODUCTION}

Cystoscopy is one of the most commonly performed urological procedures whose purpose is to inspect lower urinary tract anatomy for the purpose of evaluating lower urinary tract symptoms as well as various pathologies of the urethra, prostate and bladder. The procedure is performed by inserting an optical instrument (cytoscope) into the urethra and the bladder. The cytoscope may be metal and rigid or flexible, and its insertion may be associated with discomfort, pain and inconvenience to the patients. Therefore, physicians are sometimes reluctant to refer patients for cystoscopy, while patients may refuse to undergo this necessary urological evaluation. The aim of our study was to evaluate self-reported pain levels associated with diagnostic cystoscopy $(1,2)$ and to determine whether patients undergoing repeat cystoscopies experience less pain during those procedures. 


\section{MATERIALS AND METHODS}

Evaluation of records of all patients who underwent diagnostic cystoscopy in our institution between June 2009 and January 2010 was approved for this study by the institutional ethics committee. The patients' demographics and the procedural data were retrieved. Cases in which any other procedures (e.g., biopsy or fulguration of small tumors, uretherotomy, urethral dilation etc.) were done concurrently were excluded. Before undergoing diagnostic cystoscopy, each patient had been asked if this was the first time he/she had undergone the procedure.

All instruments were inserted and advanced under vision. The diameters of the cystoscopes were 17FR for the rigid type and 15FR for the flexible type. Lidocaine gel $2 \%$ was instilled into the urethra 1-2 minutes before the cystoscopy in men and applied on the cystoscope in women. All procedures were performed without any systemic sedation or analgesia. Five minute after the procedure, each patient was asked to grade pain levels during the index procedure on a Likert visual analog scale (VAS), where $0=$ no pain and $10=$ unbearable pain.

Descriptive statistics, such as the mean, standard deviation (SD) were used to summarize the baseline characteristics of the patients. The clinical characteristics were assessed for univariate and multivariate correlations with the risk of high pain levels (VAS > 5). The clinical parameters included age, sex, first vs. repeat cystoscopy and flexible vs. rigid cystoscope. A univariate analysis was performed by using an independent samples $t$ test or chi square. The variables that showed univariate significance $(\mathrm{P}<0.10)$ were then included in a multivariate analysis that used a logistic regression model. The analyses were carried out by using SPSS 15.0 (SPSS Inc, Chicago, Ill). Differences were regarded as statistically significant at a $\mathrm{P}$-value less than 0.05 .

\section{RESULTS}

Data were retrieved and analyzed from 1320 procedures (929 [70\%] in men and 391 [30\%] in women, mean age 63.3 years [range 15-93]) performed by 25 senior urologists. These data are summarized in Table-1. This was the first cystoscopy for 814 of the patients. A flexible cytoscope was used in 917 cystoscopies in men compared to only 56 cystoscopies in women. The overall mean pain level associated with the use of a rigid cystoscope was $2.74 \pm 1.51$ (range $0-9$ ) and $2.48 \pm$ 1.53 (range 0-10) with the use of a flexible cystoscope $(\mathrm{P}=0.004)$. The pain levels reported after the first-time cystoscopy was significantly higher than the pain levels described for the repeat ones regardless of gender $(2.8 \pm 1.6)$ or type of cys-

Table 1 - Visual analog scale pain levels stratified by age.

\begin{tabular}{lcccccc}
\hline Flexible cystoscopy & \multicolumn{7}{c}{ Rigid cystoscopy } \\
\hline & $\begin{array}{c}\text { First-time } \\
\text { Mean } \pm \text { SD (n) }\end{array}$ & $\begin{array}{c}\text { Repeat } \\
\text { Mean } \pm \text { SD }(n)\end{array}$ & P value & $\begin{array}{c}\text { First-time } \\
\text { Mean } \pm S D(n)\end{array}$ & $\begin{array}{c}\text { Repeat } \\
\text { Mean } \pm S D(n)\end{array}$ & P value \\
\hline Men & $2.8 \pm 1.6(453)$ & $2.1 \pm 1.4(364)$ & $<0.0001$ & $3.6 \pm 1.6(72)$ & $3.0 \pm 1.5(40)$ & 0.06 \\
\cline { 2 - 7 } Age $>60$ & $2.6 \pm 1.5(257)$ & $2.1 \pm 1.2(273)$ & $<0.0001$ & $3.4 \pm 1.6(40)$ & $2.9 \pm 1.4(30)$ & 0.18 \\
Age $\leq 60$ & $3.0 \pm 1.7(196)$ & $2.5 \pm 1.7(91)$ & 0.01 & $3.8 \pm 1.5(32)$ & $3.4 \pm 1.6(10)$ & 0.46 \\
Women & $1.97 \pm 1.1(38)$ & $1.8 \pm 1.2(18)$ & 0.8 & $2.7 \pm 1.4(251)$ & $2.1 \pm 1.4(84)$ & 0.003 \\
Age $>60$ & $2.2 \pm 1.3(19)$ & $2.0 \pm 1.3(13)$ & 0.6 & $2.5 \pm 1.2(123)$ & $2.1 \pm 1.6(55)$ & 0.05 \\
\hline Age $\leq 60$ & $1.6 \pm 1.0(19)$ & $1.4 \pm 0.9(5)$ & 0.6 & $2.8 \pm 1.6(128)$ & $2.2 \pm 1.2(29)$ & 0.06 \\
\hline
\end{tabular}

SD $=$ standard deviation . 
toscope used $(2.2 \pm 1.4), \mathrm{P}<0.001$. Men reported higher pains level than women $(2.6 \pm 1.5$ and 2.4 \pm 1.4 , respectively, $\mathrm{P}<0.04)$. The highest mean pain level was reported by men $(3.4 \pm 1.6)$ and women $(2.5 \pm 1.6)$ who underwent cystoscopy with a rigid cystoscope compared to cystoscopy with a flexible instrument $(2.5 \pm 1.4$ and $1.1 \pm$ 1.9 , respectively, $\mathrm{P}<0.001$ ). The 525 (57\%) men who underwent first-time cystoscopy reported a mean VAS of $2.9 \pm 1.6$, and the 404 (43\%) men who underwent repeat cystoscopy reported a significantly lower mean VAS $(2.2 \pm 1.4, \mathrm{P}<0.001)$. The 289 (74\%) women who underwent first-time cystoscopy reported a mean VAS of $2.6 \pm 1.4$ compared to the $102(26 \%)$ women who underwent a repeat cystoscopy and reported a lower mean VAS of $2.1 \pm 1.4(\mathrm{P}<0.003)$. Men younger than 60 years of age reported higher pain levels during 329 procedures compared to men older than 60 years during 600 procedures $(3.0 \pm 1.7$ vs. $2.4 \pm 1.5$, respectively, $\mathrm{P}<0.0001)$. Women of all ages reported similar pain levels during the procedure $(2.6 \pm 1.5$ in 181 women younger than 60 years vs. $2.3 \pm$ 1.3 in 210 women older than 60 years $(\mathrm{P}>0.05)$.
Pain levels (VAS > 5) were reported only in 75 of the total 1,320 cystoscopies (5.7\%). We conducted further analysis to define the factors that predict high levels of pain (Table-2). We found that "first" cystoscopy is the strongest independent predictive factor for severe pain.

\section{DISCUSSION}

Patients referred for cystoscopy often inquire about whether there is any pain associated with the procedure and about the need for and availability of general anesthesia or premedication. The answers to these questions are not always evidence-based but rather reflect the individual urologist's own perception of the pain level associated with the procedure. The International Association for the Study of Pain has proposed the following working definition: pain is"...an unpleasant sensory and emotional experience associated with either actual or potential tissue damage, or described in terms of such damage" (1). Rating acute pain using a VAS is an essential part of pain assessment. It allows some form of comparison to

Table 2 - Predictors of pain during cystoscopy.

\begin{tabular}{|c|c|c|c|c|c|}
\hline \multirow[t]{2}{*}{ Factor } & \multicolumn{2}{|c|}{ VAS pain score } & \multirow{2}{*}{$\begin{array}{l}\text { Univariate analysis } \\
\qquad(\mathrm{P} \text { value })\end{array}$} & \multicolumn{2}{|c|}{ Multivariate analysis } \\
\hline & $\begin{array}{c}>5 \\
\mathrm{n}=75\end{array}$ & $\begin{array}{c}\leq 5 \\
n=1245\end{array}$ & & $\begin{array}{l}\text { Hazard ratio } \\
(95 \% \mathrm{Cl})\end{array}$ & $(P \text { value })^{\star *}$ \\
\hline \multicolumn{6}{|l|}{ Age, years } \\
\hline Mean \pm SD & $60 \pm 14$ & $64 \pm 19$ & 0.067 & $0.99(0.97-1.0)$ & \multirow[t]{2}{*}{0.07} \\
\hline \multicolumn{5}{|l|}{ Gender, n (\%) } & \\
\hline Males & $61(81)$ & $868(70)$ & $0.032^{*}$ & 2.17 (1.19- & \multirow{2}{*}{0.011} \\
\hline Females & $14(19)$ & $377(30)$ & & 3.95) & \\
\hline \multicolumn{6}{|l|}{ Cystoscopy, n (\%) } \\
\hline Repeat & $17(23)$ & $489(39)$ & $0.004^{*}$ & $2.45(1.40-4.27)$ & \multirow{2}{*}{0.002} \\
\hline First & $58(77)$ & $756(61)$ & & & \\
\hline \multicolumn{6}{|l|}{ Cystoscope, n (\%) } \\
\hline Flexible & $24(32)$ & $423(34)$ & $0.725^{\star}$ & & \\
\hline Rigid & $51(68)$ & $822(66)$ & & & \\
\hline
\end{tabular}

${ }^{*}$ Chi-square test $\boldsymbol{\alpha}<0.05$; ${ }^{*}$ Only variables with univariate $\mathbf{P}<0.10$ were included in the multivariate analysis; VAS = visual analog scale. 
be made, and facilitates assessment of the efficacy of treatment.

This method of pain assessment in which patients grade their pain level by choosing a number between 1-10 or cartoons of "suffering faces" is well established and frequently used in the assessment of acute pain and effectiveness of pain treatment (2).

It is well accepted that cystoscopy is associated with some discomfort regardless of the type of instrument used (3), leading to the implementation of various methods to alleviate that discomfort. The introduction of a flexible cystoscope in the seventies was a great leap forward (4). Aaronson et al. (3) conducted a meta analysis and concluded that intraurethral instillation of lidocaine gel reduces the moderate to severe pain associated with flexible cystoscopy compared to plain lubricating gel. Topical lidocaine gel is now commonly used in clinical practice. Brekkan et al. (5) suggested that different amounts are needed for men and women. The use of lidocaine gel has, however, been challenged by several groups. McFarlane et al. (6) stated that the instillation of $2 \%$ lidocaine gel has no advantage over plain lubricant in providing anesthesia for flexible cystoscopy in men. Chen et al. (7) agreed, noting that pain score, pain grade, post-cystoscopic analgesic requirement, and the strength of anesthetics requested for a repeat cystoscopy were similar in men undergoing flexible cystoscopy with intraurethral 2\% lidocaine gel or with plain lubricant. Those authors recommended the use of a plain lubricant because it is less expensive and faster than applying lidocaine gel. In their meta-analysis, $\mathrm{Pa}-$ tel et al. (8) also agreed, stating that there is no statistically significant difference in the efficacy of pain control between lidocaine gel and plain gel lubrication in men during flexible cystoscopy. Losco et al. (9) considered the delaying of cystoscope insertion for few minutes in order to enhance efficacy of topical intraurethral lidocaine in pain reduction to be futile.

Others have also attempted to reduce the discomfort associated with cystoscopy. Komiya et al. (10) suggested that combining premedication oral zaltoprofen (a non-steroidal anti-inflammatory drug) with intraurethral lidocaine with impro- ved the cystoscopy-associated pain and provided a better quality of life for the patients. Calleary et al. (11) proposed that the addition of nitrous oxide inhalation for men younger than 55 years who were undergoing flexible cystoscopy. The quest for pain and anxiety relief during cystoscopy continued with Yeo et al. (12) reporting that listening to classical music during cystoscopy (using a rigid cystoscope) significantly reduced pain and discomfort levels. Zhang et al. (13) and Somooro et al. (14) observed a beneficial effect on pain level by allowing the patient to view the cystoscopy on a screen. Another attempt to reduce pain during cystoscopy by cooling the lidocaine gel installed into the urethra before the cystoscopy failed to decrease the pain level during rigid cystoscopy in male patients (15).

The various studies that addressed the issue of cystoscopy-associated pain and the alleviation of that pain were performed on a variety of populations, analgesics, pain assessment methods, instruments, etc., leading to a wide range of pain levels among them. For example, in Calleary et al. (11) report, all cystoscopies were done by a single operator, their study population was younger than 55 years, and the reported pain level was as high as 4 when lidocaine was used alone. In our current study, 25 senior urologists preformed the cystoscopies, thereby eliminating the single operator factor. Nevertheless, their results (11) are in accordance with ours: we demonstrated that men younger than 60 years of age reported higher pain levels compared to men older than 60 years. Our findings on younger patients are supported by similar results demonstrated by us in an earlier work (16) on male patients who graded their pain following urodynamic tests. Older men (> 50 years old) graded their pain level during the urodynamic pressure flow study as being lower than that of their younger counterparts, irrespective of a history of previous urodynamic procedures. Contrary to Calleary et al. (11) findings and similar to ours, Herr and Schneider (17) reported that the mean pain level during flexible cystoscopy (using linear analog self-assessment score on a scale of $1=$ none to $10=$ high) was 2.1 . Goldfischer et al. (18) recorded a mean VAS pain level of 3.00 in men and 3.1 in women during rigid cystoscopy with in- 
traurethral lidocaine, again similar to our results in men and women during their first-time cystoscopy. In their meta-analysis of the use of lidocaine during cystoscopies, Aaronson et al. (3) concluded that the mean pain level was 2-3 for men in whom lidocaine was used. This pain level is similar to the levels demonstrated in our study. Our results regarding low pain levels may be explained by the facts that in women were included in our study. In Aaronson et al. (3) meta- analysis, women were not included. Since women reported low levels of pain as compared to men, it is most likely that the overall pain levels were somehow lower. Contrary to our findings and those of others, Quiroz et al. (19) reported very low median pain levels during flexible cystoscopy (0.9) and even lower median pain levels during rigid cystoscopy (0.5).

The results of our study showed that the reported pain levels following first-time cystoscopy were significantly higher than the pain levels during repeat ones $(2.8 \pm 1.6$ vs. $2.2 \pm 1.4, \mathrm{P}<0.001)$ regardless of gender or type of cystoscope used. Pfingsten et al. (20) had demonstrated that inducing pain anticipation (by instruction) led to increased pain intensity during the test in patients with low back pain, and fear and anticipation of pain may actually increase pain perceptions in the cystoscopy setting as well.

Our study is distinctive due to its large $(1,320)$ number of consecutive cases in whom all cystoscopies were done for the diagnosis of various urethral and/or bladder pathologies. The procedures were done by a large number of urologists, thereby eliminating the bias of a single operator. All procedures were conducted with the use of local lidocaine gel 2\% as lubricant for both genders. Our study population was comprised of men and women who underwent either their first or repeat cystoscopies, unlike other reports whose subjects had only one procedure. We also compared differences in pain levels according to whether the cystoscope was rigid or flexible.

We are aware of some limitations of our study. One is that the number of previous cystoscopies and the type (rigid/flexible) of cystoscope used were not available. Another is that patients were not randomly assigned to rigid or flexible cystoscopy. A multiple number of operators could be considered as a limiting factor in this study because quality of cystoscopy done by each urologists cannot be accurately determined as variable in the analysis as compared to the study of Calleary et al. (11).

With the above-cited limitations in mind, we conclude that cystoscopy appears not to be associated with a distressing level of pain. The pain level during first-time cystoscopy is higher than in a repeated one. Using a flexible cystoscope is associated with significantly lower pain levels in both men and women and should be used in both genders of all ages.

\section{ABBREVIATIONS}

VAS $=$ visual analog scale

$\mathrm{SD}=$ standard deviation

\section{ACKNOWLEDGEMENTS}

Esther Eshkol is thanked for editorial assistance

\section{CONFLICT OF INTEREST}

None declared.

\section{REFERENCES}

1. Cook KF, Dunn W, Griffith JW, Morrison MT, Tanquary J, Sabata D, et al.: Pain assessment using the NIH Toolbox. Neurology. 2013; 80: S49-53.

2. Louly PG, Medeiros-Souza P, Santos-Neto L: N-of-1 doubleblind, randomized controlled trial of tramadol to treat chronic cough. Clin Ther. 2009; 31: 1007-13.

3. Aaronson DS, Walsh TJ, Smith JF, Davies BJ, Hsieh MH, Konety BR: Meta-analysis: does lidocaine gel before flexible cystoscopy provide pain relief? BJU Int. 2009; 104: 506-9; discussion 509-10.

4. Tsuchida S, Sugawara H: A new flexible fibercystoscope for visualization of the bladder neck. J Urol. 1973; 109: 830-1.

5. Brekkan E, Ehrnebo M, Malmström PU, Norlén BJ, Wirbrant A: A controlled study of low and high volume anesthetic jelly as a lubricant and pain reliever duringcystoscopy. J Urol. 1991; 146: 24-7.

6. McFarlane N, Denstedt J, Ganapathy S, Razvi H: Randomized trial of $10 \mathrm{~mL}$ and $20 \mathrm{~mL}$ of $2 \%$ intraurethral lidocaine gel and placebo in men undergoingflexible cystoscopy. J Endourol. 2001; 15: 541-4. 
7. Chen YT, Hsiao PJ, Wong WY, Wang CC, Yang SS, Hsieh $\mathrm{CH}$ : Randomized double-blind comparison of lidocaine gel and plain lubricating gel in relieving pain duringflexible cystoscopy. J Endourol. 2005; 19: 163-6.

8. Patel AR, Jones JS, Babineau D: Lidocaine $2 \%$ gel versus plain lubricating gel for pain reduction during flexible cystoscopy: a meta-analysisof prospective, randomized, controlled trials. J Urol. 2008; 179: 986-90.

9. Losco G, Antoniou S, Mark S: Male flexible cystoscopy: does waiting after insertion of topical anaesthetic lubricant improve patientcomfort? BJU Int. 2011; 108(Suppl 2): 42-4.

10. Komiya A, Endo T, Kobayashi M, Kim W, Araki K, Naya Y, et al.: Oral analgesia by non-steroidal anti-inflammatory drug zaltoprofen to manage cystoscopy-related pain: aprospective study. Int J Urol. 2009; 16: 874-80.

11. Calleary JG, Masood J, Van-Mallaerts R, Barua JM: Nitrous oxide inhalation to improve patient acceptance and reduce procedure related pain of flexiblecystoscopy for men younger than 55 years. J Urol. 2007; 178: 184-8; discussion 188.

12. Yeo JK, Cho DY, Oh MM, Park SS, Park MG: Listening to music during cystoscopy decreases anxiety, pain, and dissatisfaction in patients: a pilotrandomized controlled trial. J Endourol. 2013; 27: 459-62.

13. Zhang ZS, Tang L, Wang XL, Xu CL, Sun YH: Seeing is believing: a randomized controlled study from China of realtime visualization of flexiblecystoscopy to improve male patient comfort. J Endourol. 2011; 25: 1343-6.
14. Soomro KQ, Nasir AR, Ather MH: Impact of patient's self-viewing of flexible cystoscopy on pain using a visual analog scale in a randomizedcontrolled trial. Urology. 2011; 77: 21-3.

15. Bhomi KK, Rizal S, Pradhan M, Rijal A, Bhattachan CL: Pain during rigid cystoscopy: a prospective randomized controlled study comparing the benefit of cooledand room temperature lignocaine gel. Nepal Med Coll J. 2011; 13: 55-7.

16. Greenstein A, Bar-Yosef $Y$, Chen J, Matzkin H: Does information provided to men before a urodynamic study affect their expectation of pain? BJU Int. 2005; 96: 1307-9.

17. Herr HW, Schneider M: Outpatient flexible cystoscopy in men: a randomized study of patient tolerance. J Urol. 2001; 165: 1971-2.

18. Goldfischer ER, Cromie WJ, Karrison TG, Naszkiewicz L, Gerber GS: Randomized, prospective, double-blind study of the effects on pain perception of lidocaine jelly versusplain lubricant during outpatient rigid cystoscopy. J Urol. 1997; 157: $90-4$.

19. Quiroz LH, Shobeiri SA, Nihira MA, Brady J, Wild RA: Randomized trial comparing office flexible to rigid cystoscopy in women. Int Urogynecol J. 2012; 23: 1625-30.

20. Pfingsten $M$, Leibing $E$, Harter W, Kröner-Herwig $B$, Hempel D, Kronshage U, et al.: Fear-avoidance behavior and anticipation of pain in patients with chronic low back pain: a randomizedcontrolled study. Pain Med. 2001; 2: 259-66.

\footnotetext{
Correspondence address:

Alexander Greenstein, MD Department of Urology

Tel Aviv Sourasky Medical Center 6 Weizman Street Tel Aviv, 64239, Israel Fax: + 9723 697-3798

E-mail: surge04@post.tau.ac.il
} 